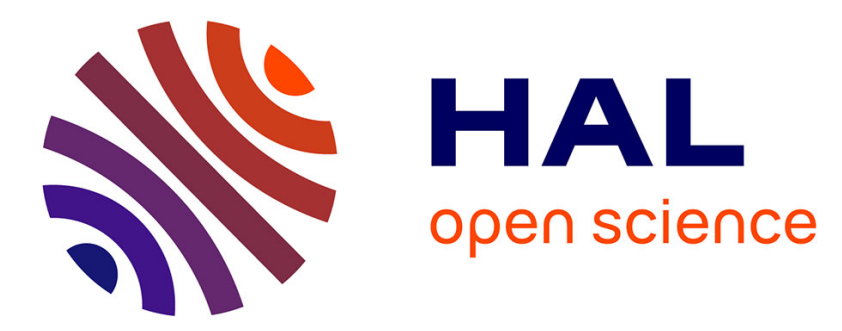

\title{
Spectroscopic properties of Er3+-doped antimony oxide glass
}

\author{
K. Ouannes, M.T. Soltani, Marcel Poulain, Georges Boulon, G. \\ Alombert-Goget, Y. Guyot, A. Pillonnet, K. Lebbou
}

\section{- To cite this version:}

K. Ouannes, M.T. Soltani, Marcel Poulain, Georges Boulon, G. Alombert-Goget, et al.. Spectroscopic properties of Er3+-doped antimony oxide glass. Journal of Alloys and Compounds, 2014, 603, pp.132 - 135. 10.1016/j.jallcom.2014.02.008 . hal-01017028v2

\section{HAL Id: hal-01017028 \\ https://hal.science/hal-01017028v2}

Submitted on 2 Jul 2014

HAL is a multi-disciplinary open access archive for the deposit and dissemination of scientific research documents, whether they are published or not. The documents may come from teaching and research institutions in France or abroad, or from public or private research centers.
L'archive ouverte pluridisciplinaire HAL, est destinée au dépôt et à la diffusion de documents scientifiques de niveau recherche, publiés ou non, émanant des établissements d'enseignement et de recherche français ou étrangers, des laboratoires publics ou privés. 


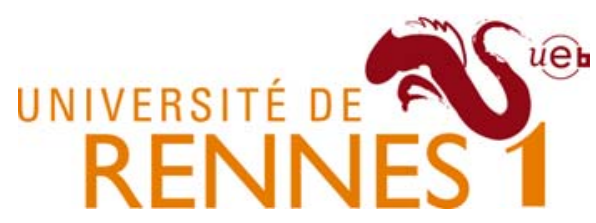

This is the author's final draft post-refeering (post-print)

Find more peer-reviewed articles on our open access repository:

http://hal-univ-rennes1.archives-ouvertes.fr/ 


\title{
Spectroscopic properties of $\mathrm{Er}^{3+}$-doped antimony oxide glass
}

\author{
K. Ouannes ${ }^{\text {a }}$, M.T. Soltani ${ }^{\mathrm{a}}$, M. Poulain ${ }^{\mathrm{b}}$, G. Boulon ${ }^{\mathrm{c}}$, G. Alombert-Goget ${ }^{\mathrm{c}}$, Y. Guyot ${ }^{\mathrm{c}}$, A. Pillonnet ${ }^{\mathrm{c}}$, \\ K. Lebbou ${ }^{\mathrm{c}, *}$ \\ ${ }^{a}$ Laboratoire de Physique Photonique et Nanomatériaux Multifonctionnels, Université de Biskra, BP 145 RP, 07000 Biskra, Algeria \\ ${ }^{\mathrm{b}}$ UMR 6226 - Verres et Céramiques - Campus de Beaulieu, Université de Rennes 1, 35042 Rennes, France \\ ${ }^{\mathrm{c}}$ Institut Lumière Matière, UMR 5306 Université Lyon 1-CNRS, Université de Lyon, 69622 Villeurbanne, France
}

\section{A B S T R A C T}

Spectroscopic properties of $\mathrm{Er}^{3+}$ ions have been studied in the $60 \mathrm{Sb}_{2} \mathrm{O}_{3}-20 \mathrm{WO}_{3}-19 \mathrm{Na}_{2} \mathrm{O}-1 \mathrm{Bi}_{2} \mathrm{O}_{3}(\mathrm{SWNB}$ ) glasses doped with 0.25 and $0.50 \mathrm{~mol} \% \mathrm{Er}_{2} \mathrm{O}_{3}$ respectively. The Judd-Ofelt parameters measured from the absorption spectra have been used to calculate the radiative life-time $\left(\tau_{r}\right)$ and the stimulated emission cross section. The low phonon energy, a reduced quenching effect and a high quantum efficiency of $90 \%$ for the $1.53 \mu \mathrm{m}$ expected laser emission into pumping at $980 \mathrm{~nm}$ are in favor of promising material laser application.

\section{Introduction}

For years, research for the improvement in the laser technology is expanding. Technology has to evolve to meet the incessant demands in wide range of applications such as basic sciences, medicine, and telecommunications. This work focuses on finding new host matrices for the rare earth ions, as their spectroscopic properties are largely used for making optical amplifiers and solid-state lasers. Among the new materials that have been widely studied in recent years, antimony oxide glasses have attracted large attention for their potential applications, especially in the field of optical amplification in the telecommunication C-band $(1530-1560 \mathrm{~nm})$ [1-6]. This group of glasses appears as one major family of Heavy Metal Oxide Glasses (HMOG). They possess low phonon energy $\left(\approx 605 \mathrm{~cm}^{-1}\right)$ and large optical non-linearity that is correlated to high refractive index [7], good mechanical properties, and better chemical durability than that of fluoride or tellurite glasses. In lanthanide-doped glasses and crystals, phonon energy is the most influential parameter in non-radiative relaxations because multiphonon decay occurs with the smallest number of phonons required to bridge the energy gap between two energy levels. Erdoped antimonite glasses free of silica and phosphorous oxide are expected to minimize the detrimental effect of the non-radiative decay.

\footnotetext{
* Corresponding author. Tel.: +33 472448329.

E-mail address: kheireddine.lebbou@univ-lyon1.fr (K. Lebbou).
}

The Judd-Ofelt (JO) theory [8,9] is used to determine the spectroscopic properties and to characterize the local environment of the lanthanide elements in antimony oxide glass. The lack of data on the structure for amorphous materials makes the problem more complex and it is still under discussion [10-12]. The intensity parameters of $\mathrm{J}-\mathrm{O}$ can have a considerable influence on the stimulated emission cross-section, fluorescence decay, and hence on the quantum efficiency of the system. These three parameters are the key factors for laser application of rare earth ions in any host matrix. To our knowledge, there are few studies based on the application of J-O theory to Er-doped antimony glasses [13]; but there is much research on the erbium-doped glasses containing $\mathrm{Sb}_{2} \mathrm{O}_{3}$ as second former in glass matrices such as antimony-borate [14,15], antimony-silicate [16] or antimony-phosphate [17].

In this work, we apply the JO theory to Er-doped antimonite glasses. Based on absorption spectrum, the stimulated emission cross section and the fluorescence decay could be determined as a function of doping level, which allows estimating the highest quantum efficiency.

\section{Experimental \\ 2.1. Sample preparation}

The composition of the glass samples used in this study is: $60 \mathrm{Sb}_{2} \mathrm{O}_{3}-20 \mathrm{WO}_{3}-$ $(19-x) \mathrm{Na}_{2} \mathrm{O}-1 \mathrm{Bi}_{2} \mathrm{O}_{3}, x \mathrm{Er}_{2} \mathrm{O}_{3}$. The selected $x$ values correspond to 0.25 and $0.5 \mathrm{~mol} \%$ Erbium concentrations. The starting materials used in the preparation of the glass are commercial powders of $\mathrm{Sb}_{2} \mathrm{O}_{3}(99+\%)$, ACROS ORGANICS, sodium carbonate $(99.8 \mathrm{~min})$ and $\mathrm{Bi}_{2} \mathrm{O}_{4}$ Prolabo WWR brand. After weighing and mixing, 
batches of $6 \mathrm{~g}$ in weight were melted in silica crucibles at a temperature close to $800{ }^{\circ} \mathrm{C}$, for $10-15 \mathrm{~min}$ in air. During the synthesis, the tube was shaken to homogenize the melt, while a release of $\mathrm{CO}_{2}$ was observed, due to the decomposition of sodium carbonate. Note that the $\mathrm{Bi}_{2} \mathrm{O}_{4}$ oxide ensures oxidizing conditions, avoiding the possible reduction of tungsten oxide. Vitreous sample were obtained by pouring the melt onto brass molds. This processing corresponds to a moderate quenching rate $(<40 \mathrm{~K} / \mathrm{s})$, followed by annealing at $300^{\circ} \mathrm{C}$ and slow cooling down to room temperature. Polishing is implemented after annealing to obtain samples of shape, thickness and surface quality suitable for optical measurements.

\subsection{Optical measurements}

Density was measured by the Archimedes method with water as the immersing liquid.

The absorption spectrum of the samples was measured by a Perkin Elmer UVVIS-NIR spectrometer operating between 200 and $3200 \mathrm{~nm}$, with a slit of $2 \mathrm{~nm}$ resolution. Photoluminescence (PL) spectra were recorded in the near-infrared (NIR) range between 1400 and $1700 \mathrm{~nm}$, under $980 \mathrm{~nm}$ laser excitation from a Ti-saphire laser. The emission spectra were measured with a CCD IDUS near-infrared InGaAs camera from ANDOR equipped with a 300 line $/ \mathrm{mm}$ grating blazed at $1000 \mathrm{~nm}$. Decay curves at the peak of the emission spectrum were recorded using 8 ns pulsed laser excitation at $980 \mathrm{~nm}$. This excitation was performed with a NT342 optical parametric oscillator pumped with a pulsed frequency-tripled Nd:YAG laser from Ekspla. The sample luminescence was focused on cooled InGaAs detector. A $1300 \mathrm{~nm}$ long pass filter was mounted on the detector to select the luminescence of the ${ }^{4} \mathrm{I}_{13 / 2} \rightarrow{ }^{4} \mathrm{I}_{15 / 2}$ transition of erbium ions. The luminescence decays were recorded by a Lecroy digital oscilloscope. The refractive index of the glass was deduced from Brewster angle measurement using goniometer.

\section{Results and discussion}

\subsection{Judd-Ofelt analysis}

Fig. 1 shows the absorption spectrum of two SWNB glasses doped with 0.25 and 0.5 mol\% $\mathrm{Er}_{2} \mathrm{O}_{3}$. The absorption spectrum consists of seven manifolds at 1530, 976, 798, 654, 544, 522, and $490 \mathrm{~nm}$, corresponding to the absorptions from the ground state ${ }^{4} \mathrm{I}_{15 / 2}$ to the excited states ${ }^{4} \mathrm{I}_{13 / 2},{ }^{4} \mathrm{I}_{11 / 2},{ }^{4} \mathrm{I}_{9 / 2},{ }^{4} \mathrm{~F}_{9 / 2},{ }^{4} \mathrm{~S}_{3 / 2},{ }^{2} \mathrm{H}_{11 / 2},{ }^{4} \mathrm{~F}_{7 /}$ 2 , respectively. The change of the bands and the consequent increase of their intensity are clearly seen as $\mathrm{Er}_{2} \mathrm{O}_{3}$ content increases. Observing the absorption of the ${ }^{4} \mathrm{I}_{13 / 2}$ manifold in $\mathrm{Er}^{3+}$ :SWNB glass shows that it exhibits a double peak structure. On the other hand, the absorption edge shifts towards lower energies with increasing $\mathrm{Er}^{3+}$ concentration, i.e., the optical energy gap of the glasses studied becomes smaller for the $0.5 \mathrm{~mol} \% \mathrm{Er}_{2} \mathrm{O}_{3}$ doped sample. If the visible edge is taken as the wavelength corresponding to the half-height of the transmission [18] for a sample $2 \mathrm{~mm}$ in thickness, then the visible edge for our glass SWNB is $\sim 416 \mathrm{~nm}$. This means that the SWNB glasses are still very transparent in the visible spectrum. Using the same definition for the infrared edge leads to a cut-off wavelength ( $50 \%$ transmission for a $2 \mathrm{~mm}$ thick sample) of $5.5 \mu \mathrm{m}$.

To obtain absorption spectra by erbium ions discriminately used for the Judd-Ofelt calculations, the measured absorption profiles of the erbium doped SWNB glasses were subtracted by the absorption profile of the undoped SWNB glass. Note that the weak peak around $850 \mathrm{~nm}$ in the absorption spectra is caused by the change of the detectors in the spectrophotometer and the rising absorption baseline in the range from 600 to $400 \mathrm{~nm}$ can be caused by the presence of bismuth ions generally observed in this region [19].

The measured absorption line strength $\left(S_{\text {meas }}\right)$ for the induced electric dipole transition of each manifold was determined using the following expression:

$S_{\text {meas }}\left(J \rightarrow J^{\prime}\right)=\frac{3 \operatorname{ch}(2 J+1)}{8 \pi^{3} \bar{\lambda} e^{2} N_{0}}\left[\frac{9 n}{\left(n^{2}+2\right)^{2}}\right] \int \alpha(\lambda) d \lambda$

where $J$ and $J^{\prime}$ represent the total angular momentum quantum numbers of the initial and final states, respectively, $e$ is the charge of the electron, $c$ the velocity of the light in the vacuum, $h$ the Planck constant, $\lambda$ is the mean wavelength of the absorption band and $N_{0}$ is

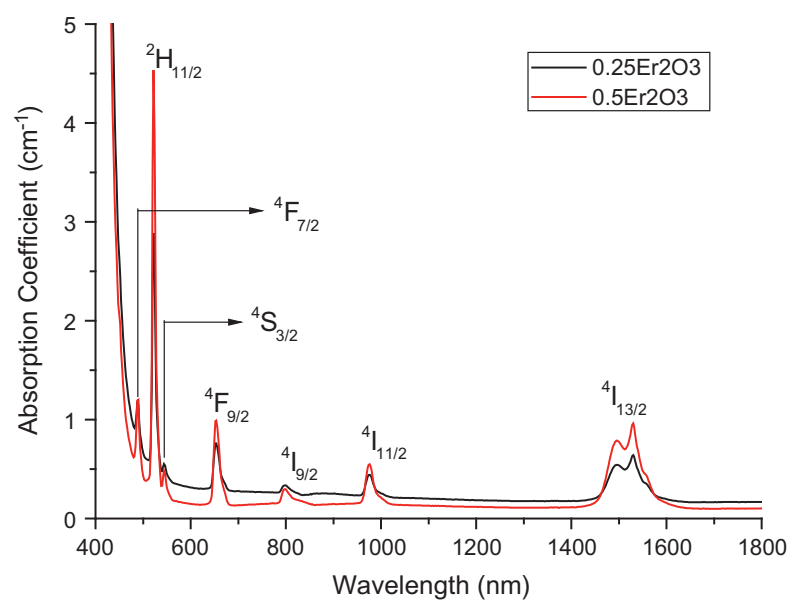

Fig. 1. Optical absorption spectrum of SWNB: $\mathrm{Er}^{3+}$.

the $\mathrm{Er}^{3+}$ ion concentration per unit volume. $\alpha(\lambda)$ is the measured absorption coefficient at a given wavelength $\lambda$. The refractive index $n$ of SWNB glass is about 1.88 determined by measuring Brewster angle. The factor in bracket represents the local field correction for $\mathrm{Er}^{3+}$ ion in the initial $J$ manifold.

Judd-Ofelt theory provides a theoretical expression for the line strength, given by:

$S_{\text {calc }}\left(J \rightarrow J^{\prime}\right)=\sum_{t=2,4,6} \Omega_{t}\left|\left\langle(S, L) J \| U^{(t)}||\left(S^{\prime}, L^{\prime}\right) J^{\prime}\right\rangle\right|^{2}$

where $\Omega_{t}$ are the Judd-Ofelt parameters and the terms in brackets are doubly reduced matrix elements in intermediate coupling approximation [20].

The best set of $\Omega_{t}$ parameters of glass were determined by a standard least square fitting of the theoretical line strength $\left(S_{\text {calc }}\right)$ values to the experimental ones $\left(S_{\text {meas }}\right)$ and are tabulated in Tables 1 and 2 . The quality of the fit was determined from the RMS deviation, and the values obtained are also listed in Table 2.

From these values, the Judd-Ofelt parameters for $\mathrm{Er}^{3+}$ :SWNB glass show the trend $\Omega_{2}>\Omega_{4} \approx \Omega_{6}$. If we compare these results to those previously reported [13], these values appear unusually large. $\Omega_{2}$ is increasing with increasing $\mathrm{Er}_{2} \mathrm{O}_{3}$ concentration, which suggests a short range structural disorder. In general, $\Omega_{2}$ increases with the asymmetry of the local structure and with the degree of covalency of the lanthanide-ligand bonds, whereas $\Omega_{6}$ decreases with the degree of covalency [21,22].

The J-O treatment that is based on the electric dipole bands leads to very large values of $\Omega_{6}$ for $\mathrm{Er}^{3+}$ ions in these glasses, by comparison to other oxide and antimony glasses previously reported [13]. The large $\Omega_{6}$ value is probably due to the low optical basicity of the glass without non bridging oxygen ions, which would be formed by incorporation of alkali ions [23]. The most polarizable elements in these glasses are the lone pairs of $\mathrm{s}^{2}$ electrons of the $\mathrm{Sb}^{3+}$ and $\mathrm{Bi}^{3+}$ cations. The local structure around $\mathrm{Er}^{3+}$ in these glasses probably contains more lone pairs than $\mathrm{WO}_{3}$-free glasses. The higher rigidity of the metal-ligand bond may also be considered.

Some important radiative properties can be calculated using the values of $\Omega_{t}$. The total spontaneous transition probability is given by:

$A_{\text {rad }}\left(J^{\prime} ; J\right)=A_{e d}+A_{m d}=\frac{64 \pi^{4} e^{2}}{3 h\left(2 J^{+1}+1\right) \bar{\lambda}^{3}} \times\left[\frac{n\left(n^{2}+2\right)^{2}}{9} S_{e d}+n^{3} S_{m d}\right]$. 
Table 1

Experimental and calculated line strengths of $\mathrm{Er}^{3+}$-doped SWNB glasses.

\begin{tabular}{|c|c|c|c|c|c|c|}
\hline \multirow[t]{2}{*}{ Transition from ${ }^{4} \mathrm{I}_{13 / 2}$ to } & \multicolumn{3}{|c|}{$0.25 \mathrm{~mol} \% \mathrm{Er}_{2} \mathrm{O}_{3}$} & \multicolumn{3}{|c|}{$0.5 \mathrm{~mol} \% \mathrm{Er}_{2} \mathrm{O}_{3}$} \\
\hline & $\overline{\bar{\lambda}(\mathrm{nm})}$ & $S_{\text {meas }}\left(10^{-20} \mathrm{~cm}^{2}\right)$ & $S_{\text {calc }}\left(10^{-20} \mathrm{~cm}^{2}\right)$ & $\bar{\lambda}(\mathrm{nm})$ & $S_{\text {meas }}\left(10^{-20} \mathrm{~cm}^{2}\right)$ & $\overline{S_{\text {calc }}\left(10^{-20} \mathrm{~cm}^{2}\right)}$ \\
\hline${ }^{4} I_{13 / 2}$ & 1520 & 3.035 & 3.055 & 1521 & 3.122 & 3.109 \\
\hline${ }^{4} \mathrm{I}_{11 / 2}$ & 988 & 0.856 & 0.941 & 984 & 1.086 & 0.965 \\
\hline${ }^{4} \mathrm{I}_{9 / 2}$ & 807 & 0.490 & 0.782 & 812 & 0.808 & 0.884 \\
\hline${ }^{4} \mathrm{~F}_{9 / 2}$ & 659 & 1.635 & 1.706 & 657 & 1.913 & 1.893 \\
\hline${ }^{4} S_{3 / 2}$ & 551 & 0.477 & 0.425 & 549 & 0.382 & 0.424 \\
\hline${ }^{2} \mathrm{H}_{11 / 2}$ & 524 & 5.468 & 5.416 & 523 & 6.180 & 6.173 \\
\hline${ }^{4} \mathrm{~F}_{7 / 2}$ & 492 & 1.557 & 1.428 & 488 & 1.371 & 1.478 \\
\hline
\end{tabular}

Table 2

Ion concentrations, J-O parameters, and rms deviations.

\begin{tabular}{|c|c|c|c|c|c|c|}
\hline $\mathrm{Er}_{2} \mathrm{O}_{3}$ conc. (mol\%) & No $\left(\times 10^{20} \mathrm{~cm}^{-3}\right)$ & $\Omega_{2}\left(\times 10^{-20} \mathrm{~cm}^{2}\right)$ & $\Omega_{4}\left(\times 10^{-20} \mathrm{~cm}^{2}\right)$ & $\Omega_{6}\left(\times 10^{-20} \mathrm{~cm}^{2}\right)$ & \multicolumn{2}{|c|}{$\mathrm{rms}\left(\times 10^{-20} \mathrm{~cm}^{2}\right)$} \\
\hline 0.25 & 0.64 & $6.46 \pm 0.30$ & $1.53 \pm 0.35$ & $1.92 \pm 0.11$ & 0.17 & This study \\
\hline 0.5 & 1.23 & $7.32 \pm 0.16$ & $1.88 \pm 0.18$ & $1.91 \pm 0.06$ & 0.09 & This study \\
\hline SNZE 0.5 & & 4.46 & 1.21 & 0.71 & & [13] \\
\hline
\end{tabular}

where $A_{e d}$ and $A_{m d}$ are the electric-dipole and magnetic-dipole spontaneous emission probabilities, respectively. The electric-dipole line strength $S_{e d}$ is calculated using (3) and presents host dependence through the $\Omega_{t}$ parameters. The magnetic-dipole line strength $S_{m d}$ can be calculated with the expression

$S_{m d}=\frac{h^{2}}{16 \pi^{2} m^{2} c^{2}}\left|\left\langle(S, L) J\|L+2 S\|\left(S^{\prime}, L^{\prime}\right) J^{\prime}\right\rangle\right|^{2}$.

All the tools have been developed up to this point, and it is now a simple matter to find the radiative lifetimes, $\tau_{r}$, and the branching ratio, $\beta$ [24],

$\frac{1}{\tau_{r}}=\sum_{J} A\left(J^{\prime}, J\right)$

$\beta_{J^{\prime} J}=\frac{A\left(J^{\prime} ; J\right)}{\sum_{J} A\left(J^{\prime} ; J\right)}$

\subsection{Fluorescence decays analysis}

The fluorescence decay time of the ${ }^{4} \mathrm{I}_{13 / 2} \rightarrow{ }^{4} \mathrm{I}_{15 / 2}$ transition can be seen in Fig. 2 . The lifetime values $\left(\tau_{\text {meas }}\right)$ listed in Table 3 were evaluated by a single exponential fit on the first decade of the decay. The lifetime values $\left(\tau_{1 / e}\right)$ evaluated at $1 / e$ of the maximum and the lifetime $\tau_{\text {int }}$ obtained by integration of the decay (tacking into account of the rise) are also reported in Table 3. A rise time due to the transition ${ }^{4} \mathrm{I}_{11 / 2} \rightarrow{ }^{4} \mathrm{I}_{13 / 2}$ can be observed in the first part of the decay (see Fig. 3 inset), $\tau_{\text {rise }}$ of $45 \mu$ s and $30 \mu$ s was evaluated for the sample doped with 0.25 and $0.5 \mathrm{~mol} \% \mathrm{Er}_{2} \mathrm{O}_{3}$, respectively. These lifetimes were used to evaluate the quantum efficiency ( $\eta=\tau_{\text {meas }} / \tau_{r}$ ) of the samples as a function of the $\mathrm{Er}_{2} \mathrm{O}_{3}$ concentration, as reported in Table 3. Here it can be seen that the measured lifetimes imply high quantum efficiencies of $90 \%$ and $73 \%$, for 0.25 and $0.5 \mathrm{~mol} \% \mathrm{Er}_{2} \mathrm{O}_{3}$, respectively. Not surprisingly, the quantum efficiency decreases as $\mathrm{Er}^{3+}$ content increases. The concentration quenching is due to the usual interactions between $\mathrm{Er}^{3+}$ ions and also the presence of $\mathrm{OH}$ impurities. The $\mathrm{OH}$ groups indicate a water contamination of the sample. This water contamination has two different origins: water adsorbed by the raw materials and contamination by air moisture during synthesis. In fact, the absorption coefficient of $\mathrm{OH}$ impurities in these glasses was found at high level, namely 8.74 and $10.3 \mathrm{~cm}^{-1}$ for 0.25 and $0.5 \mathrm{~mol} \% \mathrm{Er}_{2} \mathrm{O}_{3}$ respectively. The ratio between the values of the quantum efficiency of the two glasses is found in the order of $12 \%$, a value substantially

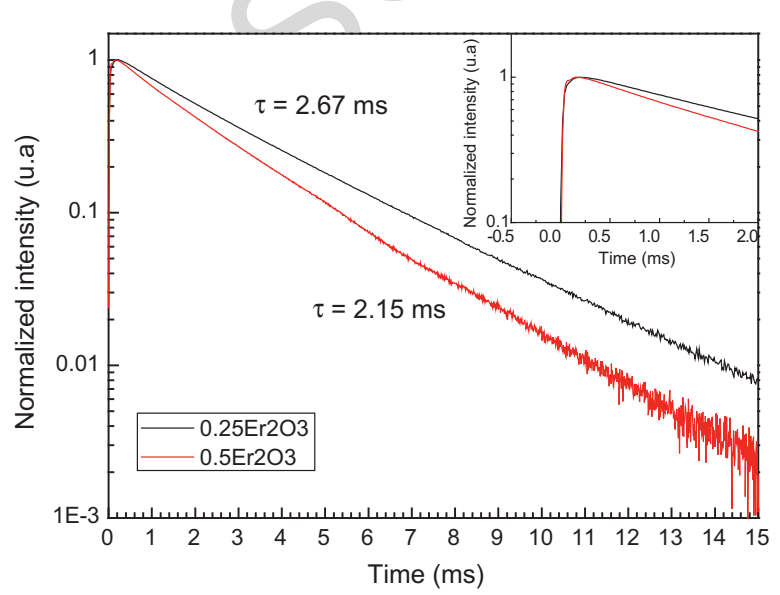

Fig. 2. Fluorescence decay time of ${ }^{4} \mathrm{I}_{13 / 2} \rightarrow{ }^{4} \mathrm{I}_{15 / 2}$ transition for $\mathrm{Er}^{3+}$ doped SWNB glass. In inset, the first two $\mathrm{ms}$ of the decay.

similar to the ratio of the absorption of the impurity $\mathrm{OH}$ coefficient in the two glasses. It has been recently proved that the content of OH-hydroxyl groups in alkali-antimonite glasses can be significantly improved by optimizing glass processing [25].

Fig. 3 shows the absorption and emission cross section spectra of $0.5 \mathrm{~mol} \% \mathrm{Er}_{2} \mathrm{O}_{3}$ doped SWNB glass. Very similar results have been obtained for the $0.25 \mathrm{~mol}_{\mathrm{E}} \mathrm{Er}_{2} \mathrm{O}_{3}$-doped sample. The emission spectra consist of the broaden lines originated from the ${ }^{4} \mathrm{I}_{13 / 2}$ lowest meta-stable Stark level to the terminal ${ }^{4} \mathrm{I}_{15 / 2}$ Stark levels with a maximum at $1530 \mathrm{~nm}$. The stimulated emission cross section can be obtained from a PL spectrum by using the Fuchtbauer-Ladenburg (F-L) expression [26] and from the absorption cross section spectrum by using the Mc-Cumber theory $[27,28]$. The F-L formula allows calculating the emission cross section $\sigma_{e m}$ spectrum from the measured PL spectrum $(I(\lambda))$ :

$\sigma_{e m}=\frac{\beta}{8 \pi n^{2} c \tau_{\text {rad }}} \frac{\lambda^{5} I(\lambda)}{\int \lambda I(\lambda) d \lambda}$

where $I(\lambda)$ is the emission spectrum intensity, $\tau_{\text {rad }}$ is the radiative lifetime, $\beta$ is the branching ratio, and $n$ is the index of refraction.

Before using this formula, the actual measured emission spectrum intensity must be corrected to account for the system response. In this way it is possible to take into account the signal 
Table 3

Emission cross section $\left(\sigma_{e m}\right)$, radiative and fluorescence decay time, and quantum efficiency $(\eta)$ of ${ }^{4} \mathrm{I}_{13 / 2} \rightarrow{ }^{4} \mathrm{I}_{15 / 2}$ transition of Er ${ }^{3+}$ doped SWNB glasses.

\begin{tabular}{|c|c|c|c|c|c|c|}
\hline $\mathrm{Er}^{3+}(\mathrm{mol} \%)$ & $\sigma_{e m_{F-L}}\left(10^{-20} \mathrm{~cm}^{2}\right)$ & $\tau_{\text {rad }}(\mathrm{ms})$ & $\tau_{\text {meas }}(\mathrm{ms})$ & $\tau_{1 / e}(\mathrm{~ms})$ & $\tau_{\text {int }}(\mathrm{ms})$ & $\eta(\%)$ \\
\hline 0.25 & 1.07 & 2.94 & 2.67 & 2.75 & 2.85 & 90 \\
\hline 0.5 & 1.07 & 2.91 & 2.15 & 2.12 & 2.22 & 73 \\
\hline
\end{tabular}

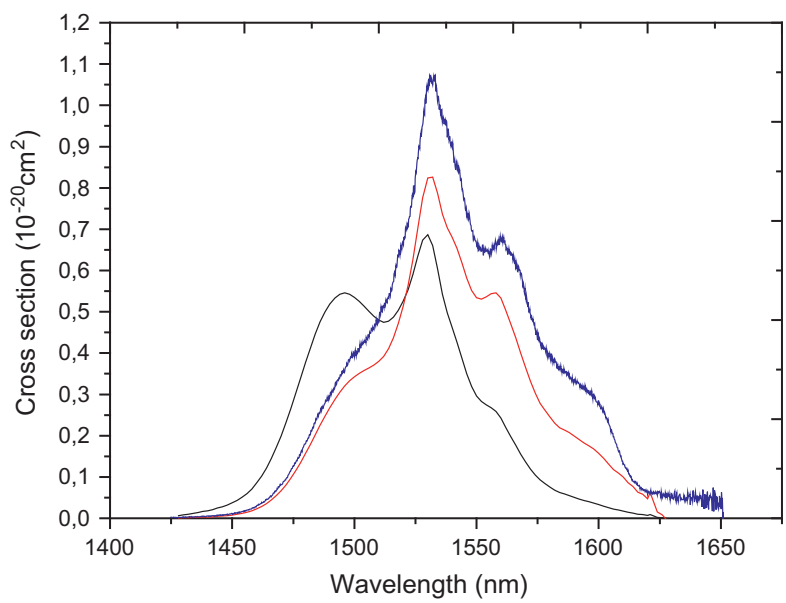

Fig. 3. ${ }^{4} \mathrm{I}_{13 / 2} \rightarrow{ }^{4} \mathrm{I}_{15 / 2}$ absorption cross section (black curve) and ${ }^{4} \mathrm{I}_{13 / 2} \rightarrow{ }^{4} \mathrm{I}_{15 / 2}$ emission cross section by $\mathrm{M}-\mathrm{C}$ (red curve) and $\mathrm{F}-\mathrm{L}$ (blue curve) formulas in the $0.5 \mathrm{~mol} \% \mathrm{Er}_{2} \mathrm{O}_{3}$-doped SWNB glass. (For interpretation of the references to colour in this figure legend, the reader is referred to the web version of this article.)

response of the experimental apparatus as a function of wavelength. By introducing a correction function $h(\lambda)$, we can write:

$L_{\text {meas }}=h(\lambda) L_{\text {real }}$

where $L_{\text {meas }}$ is the measured luminescence spectrum and $L_{\text {real }}$ is the actual luminescence spectrum.

The reciprocity of emission cross section and absorption one are related through the following equation:

$\sigma_{M C}(\lambda)=\sigma_{a}(\lambda) \frac{Z_{l}}{Z_{u}} \exp \left[\left(E_{Z L}-\frac{h c}{\lambda}\right) / k_{B} T\right]$

in which $Z_{l}$ and $Z_{u}$ are the partition functions of the lower and upper manifolds, respectively. The constants used are $h c=1 \times 10^{7}$ $\mathrm{nm} \mathrm{cm} \mathrm{cm}^{-1}$, and $k T=208 \mathrm{~cm}^{-1}$ at room temperature.

This reciprocity relationship is useful for comparing absorption and emission cross section measurements, or alternatively, driving one from the other.

In our case, the peak emission cross-section values obtained from the F-L and McCumber methods are $1.07 \times 10^{-20} \mathrm{~cm}^{2}$ and $0.82 \times 10^{-20} \mathrm{~cm}^{2}$, respectively, although the $\mathrm{F}-\mathrm{L}$ theory gives higher cross section values. This difference may be due to the uncertainties in the $Z_{l}, Z_{u}$, and $E_{Z L}$ values in the case of McCumber equation could have the effect on the final results. These values are compared with typical values reported in the literature for other glasses, such as $0.82 \times 10^{-20} \mathrm{~cm}^{2}$ for bismuth-borate [29], $0.88 \times 10^{-20} \mathrm{~cm}^{2}$ for lead halogenotellurite [18], and lower than in other glasses, such as $2.1 \times 10^{-20} \mathrm{~cm}^{2}$ for phosphate glasses [30].

\section{Conclusions}

In $\mathrm{Er}^{3+}$-doped SWNB glass, the $\Omega$ intensity parameters, the radiative lifetime, and the branching ratio have been calculated, on the base of the experimental absorption spectrum and the Judd-Ofelt theory. The high $\Omega_{2}$ Judd-Ofelt parameter in these glasses can be connected with the asymmetry of the local structure and the high degree of covalency of the lanthanide-ligand bonds. The emission cross-sections obtained from the Fuchtbauer-Ladenburg and McCumber methods are $1.07 \times 10^{-20} \mathrm{~cm}^{2}$ and $0.82 \times 10^{-20} \mathrm{~cm}^{2}$ respectively, were measured from infrared luminescence measurements, and shows similar values with bismuth-borate and lead halogeno-tellurite glasses. Luminescence decays are quasi-exponential and the measured lifetime value is very close to the radiative lifetime calculated from J-O analysis in the case of the lower doping level. In addition the quenching effect is relatively low. The calculated quantum efficiency shows that this glass could be considered for laser devices with some advantage over silicates, due to a smaller phonon energy, and larger infrared transmission at longer wavelength. By optimization of the synthesis of these glasses, especially reducing the $\mathrm{OH}$ - groups, possible applications might concern optical amplification.

\section{Acknowledgment}

We gratefully acknowledge Dr. Brian M. Walsh (NASA) for his help.

\section{References}

[1] K. Terashima, T. Hashimoto, T. Uchino, T. Yoko, J. Ceram. Soc. Jpn. 104 (1996) 1008.

[2] M. Nalin, M. Poulain, J.L. Ribeiro, Y. Messaddeq, J. Non-Cryst. Solids 284 (2001) 110.

[3] M.T. Soltani, A. Boutarfaia, R. Makhaloufi, M. Poulain, Phys. Chem. Glasses 64 (2003) 2307

[4] T.D. Holland, A.C. Hannon, M.E. Smith, C.E. Johnson, M.F. Thomas, A.M. Beesleyd, Solid State Nucl. Magn. Reson. 26 (2004) 172-179.

[5] D. Dorosz, J. Zmojda, M. Kochanowicz, J. Dorosz, J. Acta Phys. Pol. A 118 (2010) 6.

[6] P. Petkova, M.T. Soltani, S. Petkov, J. Tacheva, V. Nedkov, J. Phys. Scr. T149 (2012) 014057. 4 pp.

[7] T. Som, B. Karmakar, J. Alloys Comp. 476 (2009) 383.

[8] B.R. Judd, Phys. Rev. 127 (1962) 750.

[9] G.S. Ofelt, J. Chem. Phys. 37 (1962) 511.

[10] V. Dimitrov, Y. Dimitriev, A. Montenero, J. Non-Cryst. Solids 180 (1994) 51.

[11] S. Abiraman, H.K. Varma, T.V. Kumari, P.R. Umashankar, A. John, Bull. Mater. Sci. 25 (5) (2002) 419.

[12] J.P. Borrajo, S. Liste, J. Serra, P. Gonzalez, S. Chiussi, B. Leon, M. Perez-Amor, H.O. Ylanen, M. Hupa, Key Eng. Mater. 254-256 (2004) 23.

[13] M. Hamzaoui, M.T. Soltani, M. Baazouzi, B. Tioua, Z.G. Ivanova, R. Lebullenger, M. Poulain, J. Zavadil, J. Phys. Status Solidi B 1-9 (2012).

[14] T. Som, B. Karmakar, Opt. Mater. 31 (4) (2009) 609.

[15] Q. Qian, Q.Y. Zhang, H.F. Jiang, Z.M. Yang, Z.H. Jiang, Physica B 405 (2010) 2220.

[16] S. Tanabe, J. Alloys Comp. 408 (2006) 675.

[17] J. Zmojda, D. Dorosz, M. Kochanowicz, J. Dorosz, Photon. Lett. Poland 2 (2) (2010) 76.

[18] Yong Ding, Shibin Jiang, Bor-Chyuan Hwang, Tao Luo, Nasser Peyghambarian, Yusuke Himei, Tomoko Ito, Yoshinari Miura, Opt. Mater. 15 (2000) 123-130.

[19] E.M. Dianov, Proc. SPIE 6890 (2008) 68900H.

[20] W.T. Carnall, P.R. Fields, K. Rajnak, J. Chem. Phys. 49 (10) (1968) 15.

[21] R. Reisfeld, C.K. Jorgensen, 1987.

[22] H. Gebavi, D. Milanese, R. Balda, M. Ivanda, F. Auzel, J. Lousteau, J. Fernandez, M. Ferraris, Opt. Mater. 33 (2011) 428.

[23] S. Tanabe, T. Ohyagi, S. Todoroki, T. Hanada, N. Soga, J. Appl. Phys. 73 (1993) 8451.

[24] B.M. Walsh, Judd-Ofelt theory: principles and practices, in: B. Di Bartolo, O. Forte (Eds.), Advances in Spectroscopy for Lasers and Sensing, Springer, Netherlands, 2006, pp. 403-433.

[25] M. Baazouzi, M.T. Soltani, M. Hamzaoui, M. Poulain, J. Troles, Opt. Mater. 36 (2) (2013) 500

[26] B.F. Aull, H.P. Jenssen, IEEE J. Quantum Electron QE-18, 925 (1982).

[27] D.E. McCumber, Phys. Rev. 136 (1964) A954.

[28] S.A. Payne, L.L. Chase, L.K. Smith, W.L. Kway, W.F. Krupke, IEEE J. Quantum Electron 28 (1992) 2619.

[29] I.I. Oprea, H. Hesse, K. Betzler, Opt. Mater. 28 (10) (2005) 1136.

[30] S. Hraiech, M. Ferid, Y. Guyot, G. Boulon, J. Rare Earths 31 (7) (2013) 685. 